\title{
Degradable PRGD/PDLLA/ $\beta$-TCP/NGF composites promote differentiation and regulate gene expression in rat pheochromocytoma cells
}

\author{
QIU Tong ${ }^{1 \dagger}$, YU Chang $^{1 \dagger}$, YAN QiongJiao $^{1} \&$ LI ShiPu ${ }^{1,2^{*}}$ \\ ${ }^{1}$ Biomedical Materials and Engineering Center, Wuhan University of Technology, Wuhan 430070, China; \\ ${ }^{2}$ State Key Laboratory of Advanced Technology for Materials Synthesis and Processing, Wuhan University of Technology, Wuhan 430070, China
}

Received June 26, 2012; accepted August 8, 2012; published online June 27, 2013

\begin{abstract}
In this study, we synthesized degradable PRGD/PDLLA/ $\beta$-TCP/NGF composites to facilitate neuronal repair. To this end, we (1) examined the release of nerve growth factor (NGF) from the composites, (2) evaluated the differentiation status of the cells and (3) address how transcriptional activity may regulate the differentiation mechanism of these cells. NGF content was determined using enzyme-linked immunosorbent assay, while the cellular mRNA expression was examined by real-time PCR analysis. Our results indicated that NGF release was robust during the first 10 days and then stabilized at a lower level thereafter. Treatment of PC12 cells with the extract of the NGF-embedded composites induced the formation of neurites and, in some cases, net-like neurites. Analysis of the expression level of differentiation-related genes, such as TrkA, VGF, Rab1, GAP43 and $\beta$-tubulin II, were significantly up-regulated. These findings suggest that these composites might be a suitable delivery system for growth factors like NGF that can be used to facilitate neuronal repair after injury.
\end{abstract}

nerve guidance conduit, nerve growth factor, neuronal repair, PC12 cells

Citation: Qiu T, Yu C, Yan Q J, et al. Degradable PRGD/PDLLA/ $\beta$-TCP/NGF composites promote differentiation and regulate gene expression in rat pheochromocytoma cells. Chin Sci Bull, 2013, 58: 2979-2983, doi: 10.1007/s11434-013-5805-3

Synthetic nerve guide conduits with sustained release of nerve growth factor (NGF) are valuable in the treatment of peripheral nerve injury [1]. A novel nerve guidance conduit comprising poly\{(lactic acid)-co-[(glycolic acid)-alt- $(L-$ lysine)]\} (PRGD), poly (d,1-lactic acid) (PDLLA), $\beta$-tricalcium phosphate $(\beta$-TCP), and NGF was synthesized by embedding NGF into degradable composites [2]. The main compositions and their functions are shown in Table 1. The NGF content in the composites was $70 \mu \mathrm{g} / \mathrm{g}$, while the arginine-glycine-aspartate (RGD) peptide content was 6.9 $\mu \mathrm{mol} / \mathrm{g}$. Previously, we showed that Schwann cells remained healthy when cultured with these composites, which indicated good cell affinity and biocompatibility [8]. In animal experiments, the composites also showed good biocompatibility and facilitated nerve regeneration bridging a

\footnotetext{
$\dagger$ These authors contributed equally to this work.
}

*Corresponding author (email: lishipu46@126.com) sciatic nerve defect [9]. However, currently it is unclear how these NGF-embedded composites affect neuronal cell differentiation and how the composites function during peripheral nerve repair.

The rat pheochromocytoma cell line (PC12) is widely used to investigate mechanisms regulating neuronal differentiation. In response to $\mathrm{NGF}, \mathrm{PC} 12$ cells differentiate into sympathetic neuron-like cells. Throughout the differentiation process, NGF induces the expression of many genes. In this study, we evaluated the effect of NGF-embedded composite extract on the expression of five neuronal differentiation-related genes: TrkA, VGF, Rabl, GAP43 and $\beta$-tubulin II.

TrkA is a receptor tyrosine kinase with high-affinity receptor for NGF that activates the Ras-MAPK signaling pathway to regulate PC12 cell differentiation [10,11]. TrkA mRNA expression is increased by NGF addition [12,13]. $V G F$ is a NGF-specific response gene. It has been reported 
Table 1 Main composition of the composite and their functions used for synthesizing the nerve guidance conduit ${ }^{\text {a) }}$

\begin{tabular}{|c|c|}
\hline $\begin{array}{c}\text { Names of main } \\
\text { compositions }\end{array}$ & Function \\
\hline PDLLA & $\begin{array}{l}\text { superior biodegradability and high mechanical } \\
\text { properties, excellent delivery systems }[3,4]\end{array}$ \\
\hline PRGD & improve the cell attachment and growth [5] \\
\hline$\beta$-ТCP & $\begin{array}{l}\text { balance out the acid degradation product of PDLLA } \\
\text { and change the solubility of calcium [6] }\end{array}$ \\
\hline NGF & $\begin{array}{l}\text { a neurotrophic protein predominantly acting on senso- } \\
\text { ry and sympathetic neurons, promoted nerve regener- } \\
\text { ation [7] }\end{array}$ \\
\hline
\end{tabular}

a) PLLA: poly(d, l-lactic acid); $\beta$-TCP: $\beta$-tricalcium phosphate; NGF: nerve growth factor; PRGD: RGD peptide modification of poly \{(lactic acid)-co-[(glycolic acid)-alt-( $L$-lysine $)]\}$.

that $V G F$ mRNA was rapidly and markedly induced by neurotrophins such as NGF, peaking during axonal outgrowth and synaptogenesis [14]. Rab1 is a vesicular trafficking protein. During NGF-induced neurite extension, Rab1 is enriched in neurites and predominantly enriched in growth cones [15]. Cell differentiation is also accompanied by prominent changes in the expression of cell structure-related proteins to regulate morphological changes. NGF has been demonstrated to regulate the expression of cytoskeletal proteins such as $\beta$-tubulin $I I$ and regulatory proteins like GAP-43 in PC12 cells $[16,17]$. In this study, we investigated the release of NGF from NGF-embedded composites and evaluated its effects on PC12 cell differentiation.

\section{Materials and methods}

\subsection{NGF released assay}

PRGD/PDLLA/ $\beta$-TCP/NGF and PRGD/PDLLA/ $\beta$-TCP films were synthesized as described previously [2]. Pieces of NGF-embedded composites (weighing 100 mg, $n=5$ ) were immersed in $3 \mathrm{~mL}$ of phosphate buffered saline (PBS, $\mathrm{pH}$ 7.4) and incubated at $37^{\circ} \mathrm{C}$ on an orbital shaker (100 $\mathrm{r} / \mathrm{min})$. The supernatant was removed daily and replaced with an equal volume of fresh PBS. The NGF concentration in the daily supernatant sample was measured by an enzyme-linked immunosorbent assay (ELISA) kit (Promega,
Wisconsin, USA). The concentration was calculated as the total NGF content per total mass of the composite.

\subsection{Extract of the composites}

PRGD/PDLLA/ $\beta$-TCP/NGF and PRGD/PDLLA/ $\beta$-TCP films were sterilized with ultraviolet light for $30 \mathrm{~min}$ on each side. Pieces of the two composites were extracted with RPMI 1640 (Hyclone, Utah, USA) complete media for $24 \mathrm{~h}$. Then, the supernatants were collected and diluted four-fold with RPMI 1640 complete media and stored at $-70^{\circ} \mathrm{C}$.

\subsection{Cell culture and treatments}

PC12 cells were obtained from China Center for Type Culture Collection (Wuhan, China) and cultured at $37^{\circ} \mathrm{C}$ at $5 \%$ $\mathrm{CO}_{2}$ in RPMI 1640 complete media supplemented with $10 \%$ horse serum (HS: Gibico/BRL, New York, USA), 5\% fetal bovine serum (FBS: Gibico/BRL), $100 \mathrm{U} / \mathrm{mL}$ penicillin and $100 \mathrm{ng} / \mathrm{mL}$ streptomycin (Invitrogen, Carlsbad, USA). PC12 cells were seeded on tissue culture plates that had been previously treated with $1.0 \mathrm{mg} / \mathrm{mL}$ poly- $L$-lysine (Sigma; St. Louis, MO, USA) for $4 \mathrm{~h}$. The following day, an equal number of cells were divided into 4 groups $(n=3)$ and treated with different culture media: (A) RPMI 1640 complete medium with $50 \mathrm{ng} / \mathrm{mL} \mathrm{NGF}$; (B) RPMI 1640 complete medium without NGF (control group); (C) extract of NGF-embedded composites; (D) extract of composites without NGF. After 3 days of culture, we obtained random microscopic images of PC12 cells under a light microscope (Olympus, Tokyo, Japan). Three sampling points were set in the experiment $(1,2$ and $3 \mathrm{~d})$. Three parallel samples were made for each group and quickly frozen and stored in liquid nitrogen.

\subsection{Quantitative real-time PCR}

Total RNA was isolated from cells using Trizol reagent (Invitrogen) and was reverse transcribed into cDNA. All the primers used in the quantitative PCR (qPCR) analysis are listed in Table 2. Some of the primers were designed based on the gene sequences of Rattus norvegicus present

Table 2 Real-time PCR primers used in this experiment ${ }^{\text {a) }}$

\begin{tabular}{lcc}
\hline \multirow{2}{*}{ Gene name } & Primer sequence $\left(5^{\prime} \rightarrow 3^{\prime}\right)$ & \multicolumn{2}{c}{ Product size } \\
\cline { 2 - 3 } TrkA $*$ & Forward primer & Reverse primer \\
Tubulin-2* & GGGGCTAACTCTGGTCAAT & ATGCTGTTCCACGGCTTT \\
Rabl $\#$ & CCCAACAATGTGAAGACGG & GCCTCGGTGAACTCCATCT \\
$V G F \#$ & GAGCCCATGGCATCATAGTT & CATTCGTTGCGTTCTTAGCA \\
GAP-43\# & GTGTCTGTCTCCCAGCCTTG & ATTTCCTCCGTGAGGGGTAT \\
GAPDH $\#$ & CCGACAGGATGAGGGTAAAG & GCAGGAGAGACAGGGTTC \\
\hline
\end{tabular}

a) * Primers were designed by Primer Premier 5.0; \# Primers were cited from references [17,18]. 
on the NCBI homepage (http://www.ncbi.nlm.nih.gov), while others were obtained from references $[17,18]$. Conditions for qPCR were previously described [19]. After completion of the qPCR amplification, data were analyzed with the Bio-Rad CFX manager software version 1.0 and fold difference was calculated using the $2^{-\Delta \Delta C_{\mathrm{T}}}$ method.

\subsection{Statistical analysis}

All values were expressed as mean \pm standard deviation. One-way ANOVA was performed to evaluate differences among treatment groups and the control group $(P<0.05)$.

\section{Results and discussion}

\subsection{PC12 cell morphological changes after treatment with composite extract}

Figure 1 shows PC12 cells from the 4 groups after 3 days of treatment. Differentiated cells were defined as those with neurites longer than the soma diameter [20]. Most of the PC12 cells were differentiated in RPMI 1640 complete medium with $50 \mathrm{ng} / \mathrm{mL}$ NGF (Figure 1(a)) and in the extract of NGF-embedded composites (Figure 1(c)). The majority of these cells possessed more than one neurite or even featured net-like neurites. By contrast, cells cultured in the extract of the PRGD/PDLLA/ $\beta$-TCP composite without NGF or in the complete media without NGF groups remained round and undifferentiated after 3 days of treatment.

\subsection{Release kinetics of NGF}

We measure the amount of NGF released from the $\mathrm{PRGD} / \mathrm{PDLLA} / \beta$-TCP/NGF films in vitro for $15 \mathrm{~d}$ (Figure $2)$. On the first day, there was a robust release of NGF

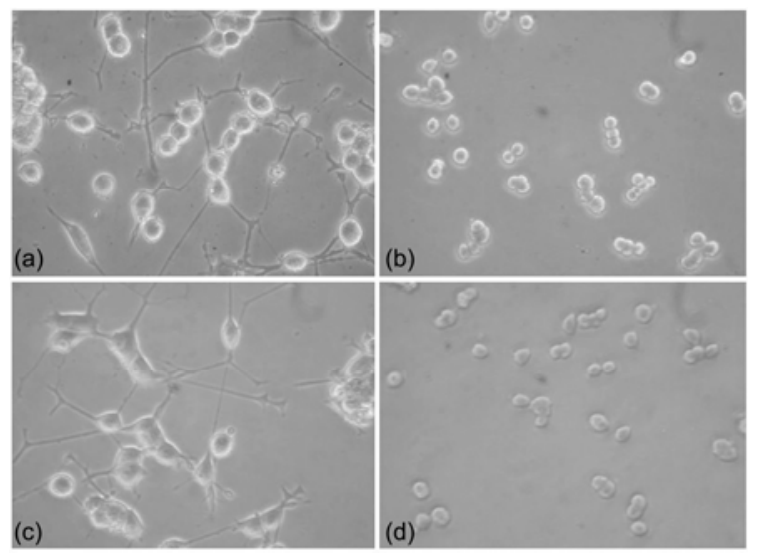

Figure 1 Morphological differentiation of PC12 cells after treatments (400× magnification). (a) RPMI 1640 complete medium with $50 \mathrm{ng} / \mathrm{mL}$ NGF; (b) RPMI 1640 complete medium without NGF (control group); (c) extract of PRGD/PDLLA/ $\beta$-TCP/NGF composites; (d) extract of PRGD/ PDLLA $/ \beta$-TCP composites.
$(13.575 \pm 3.569 \mathrm{ng} / \mathrm{mg}$ film). The release rate of NGF slowed thereafter to $0.118 \pm 0.011 \mathrm{ng} / \mathrm{mg}$ film by the day 10 . After this, the NGF that was released from the composites was less than $0.1 \mathrm{ng} / \mathrm{mg}$ films per day for the subsequent 5 days. By day 15, NGF could still be detected at $0.066 \pm 0.012$ $\mathrm{ng} / \mathrm{mg}$ film. According to the diffusion-degradation based delivery system [21], the NGF-embedded composite is a suitable delivery system for NGF.

In our study, the NGF release curve showed two distinctive stages with different slopes: in the first 10 days, the curve started with a prominent decline accompanied by a gradual reduced release rate; after 10 days, the curve plateaued at a steady level. It is possible that the porous structure of the PRGD/PDLLA/ $\beta$-TCP/NGF composites promotes the rapid release of NGF. At early stages, NGF adhering to the surface of composites was first released [6]. Then, after 10 days, the release rate of NGF maintained at a low steady level dependent on the degradation of the PRGD/PDLLA/ $\beta$-TCP/NGF composite. We calculated that the NGF concentration in the extract applied in cell culture was $\sim 28 \mathrm{ng} / \mathrm{mL}$.

\section{3 mRNA expression levels of cell differentiation- related genes}

Using qPCR analysis, we detected a significant up-regulation of the transcription of five genes related to cells differentiation when exposed to the extract of NGF-embedded composites. The peak of this expression for all the genes was at day 2. By contrast, the expression level of these genes where unchanged when treated with extract or from the composite or media without NGF.

As shown in Figure 3, the expression of TrkA increased after treatment with NGF. This increase was most prominent at day 2 and remained steady at day 3 in the NGFembedded composite group. In these studies, the TrkA mRNA was equally induced by both the composite and media containing NGF. This indicates that the NGF released from the composite is as effective as soluble NGF in promoting TrkA expression.

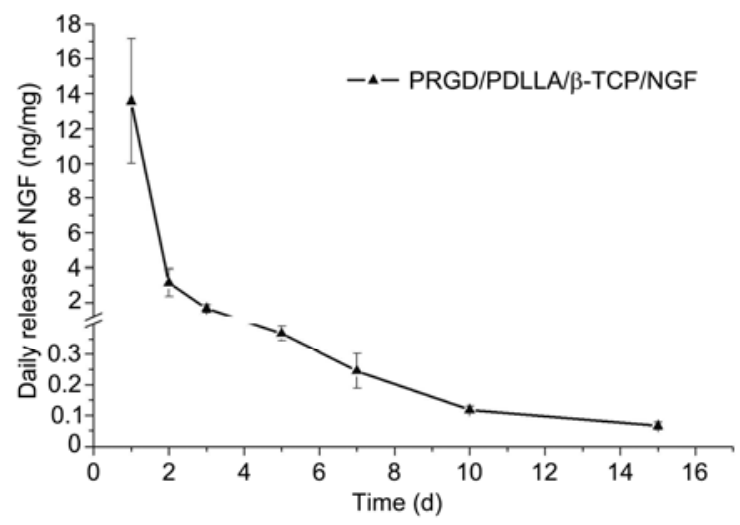

Figure 2 The release of NGF from PRGD/PDLLA/ $\beta$-TCP/NGF composites over time in vitro. 

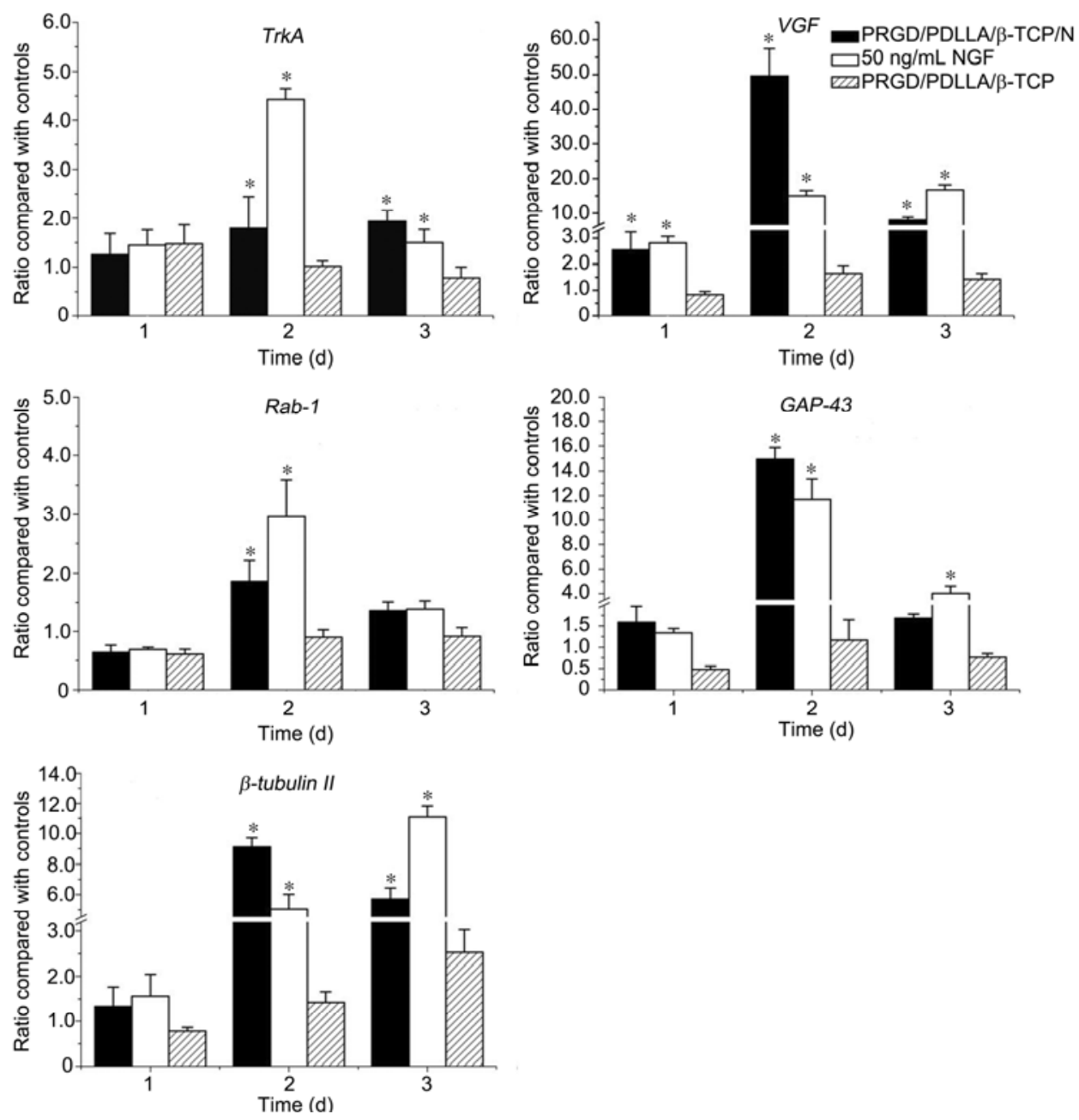

Figure 3 Time course of TrkA, VGF, Rabl, GAP-43 and $\beta$-tubulin II mRNA expression by real-time quantitative PCR analysis in PC12 cells after the indicated treatments. $* P<0.05$.

Figure 3 shows the transcriptional changes observed for $V G F$ for the first 3 days. There was a high expression of the $V G F$ mRNA detected in both groups with NGF. Surprisingly, however, the $V G F$ mRNA in the NGF-embedded composite group showed a three-fold higher level of expression compared with the $50 \mathrm{ng} / \mathrm{mL}$ NGF group on day 2 . Our results demonstrated that $V G F$ mRNA levels were maximally induced to $\sim 16$-fold, which was in agreement with a previous report [22]. However, polarization can also lead to a rapid increase in $V G F$ mRNA expression level by triggering calcium influx through voltage-gated calcium channels [22,23]. During the degradation of the composites, $\beta$-TCP elevates the calcium concentration in the culture medium, which is involved in mediating the growth and migratory direction of axons. Therefore, this increase in extracellular calcium likely promotes calcium influx into the cell and further enhances $V G F$ mRNA expression in the PRGD/PDLLA//3-TCP/NGF group.

We also noted that Rabl mRNA expression levels increased in our study (Figure 3), comparable with the result from Ragna et al. [24]. We observed a 4-fold increase in
Rab1 mRNA levels after NGF stimulation from the composite versus a 2.9-fold increase in protein expression in the $50 \mathrm{ng} / \mathrm{mL}$ group. In both NGF groups, however, the levels of Rabl were only transiently elevated at day 2 , returning to control levels at day 3.

GAP-43 plays a prominent role in neuronal differentiation by regulating the extension and maintenance of neurites induced by neurogenic factors such as NGF [25]. Recently, qPCR and microarray analysis has shown that GAP-43 mRNA expression steadily rose within 4 days after NGF addition in Ns-PC12 cells, which was coincident with the morphological extension of neurites [18]. In this study, we found that GAP-43 mRNA was strongly increased at day 2 in the PRGD/PDLLA/ $\beta$-TCP/NGF group and returned to control levels at day 3 (Figure 3). By contrast, $50 \mathrm{ng} / \mathrm{mL}$ soluble NGF promoted a similar increase in GAP-43 mRNA levels at day 2 that was maintained at day 3. Nonphosphorylated GAP-43 is served as a calmodulin trap, sequestering the calcium-binding protein and keeping it inaccessible [26]. One possible reason for this difference might be that the increased calcium concentration from the degra- 
dation of $\beta$-TCP in the composites leads to the augment of binding between GAP-43 and the calmodulin. Regardless of this observation, however, the morphological changes of cells in both groups were similar at day 3 .

Finally, we also found that the levels of $\beta$-tubulin II mRNA expression were also significantly elevated at day 2 and steadily increased in at day 3 when PC12 cells were exposed to $50 \mathrm{ng} / \mathrm{mL}$ NGF. Similar results was reported by Dijkmans et al. [18], who revealed an up-regulation of $\beta$-tubulin II mRNA both by microarray and qPCR analysis. There was also a strong up-regulation in $\beta$-tubulin II mRNA levels in the NGF-embedded composite group at day 2, even higher than that observed in the $50 \mathrm{ng} / \mathrm{mL}$ group. However, unlike the $50 \mathrm{ng} / \mathrm{mL}$ group, the levels of $\beta$-tubulin II mRNA in the NGF-embedded composite group did not further increase at day 3 . This earlier shift in peak expression is likely related to the robust early release of NGF in the composite group $(\sim 100 \mathrm{ng} / \mathrm{mL})$.

\section{Conclusions}

In conclusion, the novel composite presented in this study showed an effective release of NGF on the first day and maintained a steady release thereafter. Furthermore, the extract of this composite promoted PC12 cell differentiation and stimulated the expression of differentiation-related genes such as TrkA, VGF, Rabl, GAP-43, and $\beta$-tubulin II. Along with our previous data demonstrating the biocompatibility of this composite $[8,9]$, these results suggest the PRGD/PDLLA/ $\beta$-TCP/NGF composite should be suitable as a delivery system for growth factors such as NGF that may facilitate neuronal in the peripheral nervous system.

This work was supported by the National Basic Research Program of China (2011CB606205).

1 Xua X Y, Yeeb W C, Hwang P Y K, et al. Peripheral nerve regeneration with sustained release of poly (phosphoester) microencapsulated nerve growth factor within nerve guide conduits. Biomaterials, 2003, 24: 2405-2412

2 Yan Q J, Li J, Li S P, et al. Synthesis and RGD peptide modification of poly\{(lactic acid)-co-[(glycolic acid $)$-alt- $(L-l y s i n e)]\}$. e-Polymers, 2008, 28: 1-12

3 Zeng J, Xu X Y, Chen X S, et al. Biodegradable electrospun fibers for drug delivery. J Control Release, 2003, 92: 227-231

4 Gilding D K, Reed A M. Biodegradable polymers foruse in surgery-polyglycolic/poly (actic acid) homo- and copolymers. Polymer, 1979, 20: 1459-1464

5 Cook A D, Hrkach J S, Gao N N, et al. Characterization and development of RGD-peptide-modified poly (lacticacid-co-lysine) as an interactive, resorbable biomaterial. J Biomed Mater Res A, 1997, 35: 513-523

6 Wang Y H, Yin Y X, Dai H L, et al. Evaluation of a novel bioab- sorbable PRGD/PDLLA/ $\beta$-TCP/NGF composites in repair of peripheral nerves. J Wuhan Univ Technol-Mater Sci Ed, 2009, 24: 409-414

7 Derby A, Engleman V W, Frierdich G E, et al. Nerve growth factor facilitates regeneration across nerve gaps: Morphological and behavioral studies in rat sciatic nerve. Exp Neurol, 1993, 119: 176-191

8 Wang Y H, Yin Y X, Yan Q J, et al. Biocompatibility estimation of RGD macromolecule biomaterials for restoring peripheral nerve. Asia-Pacific Traditional Medicine, 2008, 4: 15-18

9 Wan Z T, Yin Y X, Wang Y H, et al. Research on the release of nerve growth factor from PNGF nerve repair material in vitro. $\mathrm{J} \mathrm{Wu}$ han Univ Technol-Mater Sci Ed, 2010, 32: 19-21

10 Cowley S, Paterson H, Pauline K, et al. Activation of MAP kinase kinase is necessary and sufficient for PC12 differentiation and for transformation of NIH 3T3 cells. Cell, 1994, 77: 841-852

11 Loeb D M, Maragos J, Martin-Zanca D, et al. The trk proto-oncogene rescues NGF responsiveness in mutant NGF-nonresponsive PC12 cell lines. Cell, 1991, 66: 961-966

12 Gage F H, Batchelor P, Chen K S, et al. NGF receptor reexpression and NGF-mediated cholinergic neuronal hypertrophy in the damaged adult neostriatum. Neuron, 1989, 2: 1177-1184

13 Holtzman D M, Li Y W, Parada L F, et al. p140 trk mRNA marks NGF-responsive forebrain neurons: Evidence that $t r k$ gene expression is induced by NGF. Neuron, 1992, 9: 465-478

14 Snyder S E, Pintar J E, Salton S R J. Developmental expression of VGF mRNA in the prenatal and postnatal rat. J Comp Neurol, 1998, 392: 64-90

15 Sannerud R, Marie M, Nizak C, et al. Rab1 defines a novel pathway connecting the pre-Golgi intermediate compartment with the cell periphery. Mol Biol Cell, 2006, 17: 1514-1526

16 Drubin D G, Feinstein S C, Shooter E M, et al. Nerve growth factor-induced neurite outgrowth in PC12 cells involves the coordinate induction of microtubule assembly and assembly-promoting factors. J Cell Biol, 1985, 101: 1799-1807

17 Baetgend E E, Hammangt J P. Neurite outgrowth in PC12 cells deficient in GAP-43. Neuron, 1991, 6: 21-30

18 Dijkmans T F, Van Hooijdonk L W A, Schouten T G, et al. Temporal and functional dynamics of the transcriptome during nerve growth factor-induced differentiation. J Neurochem, 2008, 105: 2388-2403

19 Xiong Q, Xie P, Li H Y, et al. Acute effects of microcystins exposure on the transcription of antioxidant enzyme genes in three organs (liver, kidney and testis) of male Wistar rats. J Biochem Mol Toxic, 2010, 24: $361-367$

20 Meilander N J, Yu X J, Ziats N P. Lipid-based microtubular drug delivery vehicles. J Control Release, 2001, 71: 141-152

21 Chen P R, Chen M H, Lin F H, et al. Release characteristics and bioactive assessment of novel GTG membrane covalently immobilized with nerve growth factors. Biomaterials, 2005, 26: 6579-6587

22 Salton S R J, Fischberg D J, Dong K W. Structure of the gene encoding $V G F$, a nervous system-specific mRNA that is rapidly and selectively induced by nerve frowth factor in PC12 cells. Mol Cell Biol, 1991, 11: 2335-2349

23 Tatsuro K, Martin D P, Johnson E M. Role of $\mathrm{Ca}^{2+}$ channels in the ability of membrane depolarization to prevent neuronal death induced by trophic-factor deprivation: Evidence that levels of internal $\mathrm{Ca}^{2+}$ determine nerve growth factor dependence of sympathetic ganglion cells. Proc Natl Acad Sci USA, 1989, 86: 6421-6425

24 Ragna S, Michael M, Clement N, et al. Rab1 defines a novel pathway connecting the Pre-Golgi intermediate compartment with the cell periphery. Mol Biol Cell, 2006, 17: 1514-1526

25 Benowitz L I, Aryeh R. GAP-43: An intrinsic determinant of neuronal development and plasticity. Trends Neurosci, 1997, 20: 84-91

26 Liu Y C, Storm D R. Regulation of free calmodulin levels by neuromodulin: Neuron growth and regeneration. Trends Pharmacol Sci, 1990, 11: 107-110

Open Access This article is distributed under the terms of the Creative Commons Attribution License which permits any use, distribution, and reproduction in any medium, provided the original author(s) and source are credited. 